\title{
Wnt signaling induces epithelial-mesenchymal transition with proliferation in ARPE-19 cells upon loss of contact inhibition
}

\author{
Hung-Chi Chen ${ }^{1,2, *}$, Ying-Ting Zhu ${ }^{1, *}$, Szu-Yu Chen ${ }^{1}$ and Scheffer CG Tseng ${ }^{1}$
}

Proliferation and epithelial-mesenchymal transition (EMT) of the retinal pigment epithelium (RPE) are hallmarks of proliferative vitreoretinopathy. This study aims at clarifying the role of growth factors, such as epidermal growth factor (EGF), fibroblast growth factor-2 (FGF-2), and transforming growth factor- $\beta 1$ (TGF- $\beta 1$ ), in controlling how RPE proliferates while undergoing EMT. When contact inhibition of post-confluent ARPE-19 cells was disrupted by EGTA, an increase of BrdU labeling was noted only in the presence of EGF and/or FGF-2, and was accompanied by EMT as evidenced by the loss of a normal RPE phenotype (altered cytolocalization of RPE65, N-cadherin, ZO-1, and Na,K-ATPase) and the gain of a mesenchymal phenotype (increased expression of vimentin, S100A4, and $\alpha$-smooth muscle actin). EMT with proliferation by EGTA + EGF + FGF-2 was accompanied by activation of canonical Wnt signaling (judged by the TCF/LEF promoter activity, increased nuclear levels of and interaction between $\beta$-catenin and LEF1 proteins, and the replication by overexpression of $\beta$-catenin), abolished by concomitant addition of XAV939, a Wnt inhibitor, but not associated with suppression of Hippo signaling (negative expression of nuclear TAZ or YAP and cytoplasmic $\mathrm{p}$-TAZ or p-YAP). The causative role of Wnt signaling on EMT with proliferation was confirmed by overexpression of stable S33Y $\beta$-catenin with EGTA treatment. In addition, contact inhibition disrupted by EGTA in the presence of TGF- $\beta 1$ also led to EMT, but suppressed proliferation and Wnt signaling. The Wnt signaling triggered by EGF + FGF-2 was sufficient and synergized with TGF- $\beta 1$ in activating the Smad/ZEB1/2 signaling responsible for EMT. These findings establish a framework for further dissecting how RPE might partake in a number of proliferative vitreoretinopathies characterized by EMT. Laboratory Investigation (2012) 92, 676-687; doi:10.1038/labinvest.2011.201; published online 5 March 2012

KEYWORDS: ARPE-19 cells; contact inhibition; epithelial-mesenchymal transition; proliferation; Smad; Wnt signaling; ZEB

The retinal pigment epithelium (RPE), a monolayer of cuboidal cells resting on the Bruch's membrane, plays a pivotal role in maintaining photoreceptor functions (reviewed by Strauss ${ }^{1}$ ). In vivo, the RPE monolayer is differentiated and mitotically quiescent, presumably due to contact inhibition (reviewed by Binder et $a l^{2}$ ). Experimentally, such contact inhibition also exists in primary human RPE cell cultures ${ }^{3}$ and RPE explant cultures. ${ }^{4}$ Clinically, epithelial-mesenchymal transition (EMT), which represents the loss of epithelial phenotype such as expression of E-cadherin and cytokeratins, and the gain of mesenchymal phenotype, such as expression of vimentin, S100A4, and $\alpha$-smooth muscle actin ( $\alpha$-SMA) (reviewed by Kalluri and Weinberg ${ }^{5}$ ), can occur in a number of pathological diseases involving RPE (reviewed by Saika et $\mathrm{al}^{6}$ ). One such example is proliferative vitreoretinopathy, in which RPE undergoes EMT to become fibroblastic and contractile cells leading to tractional retinal detachment and blindness (reviewed by Nagasaki et $a l^{7}$ and Pastor et $a l^{8}$ ). Importantly, the detrimental outcome of proliferative vitreoretinopathy is also attributed to proliferation of abnormal RPE. ${ }^{7}$ It remains unclear whether RPE proliferation in EMT is causatively linked to the loss of contact inhibition

\footnotetext{
${ }^{1}$ Tissue Tech, R\&D Ocular Surface Center, Ocular Surface Research and Education Foundation, Miami, FL, USA and ${ }^{2}$ Department of Ophthalmology, Chang Gung Memorial Hospital (Linkou) and Graduate Institute of Clinical Medical Sciences, Chang Gung University, Taoyuan, Taiwan, ROC

Correspondence: Professor SCG Tseng, MD, PhD, Tissue Tech, R\&D Ocular Surface Center, Ocular Surface Research and Education Foundation, 7000, SW 97th Avenue, Suite 213, Miami, FL 33173, USA.

E-mail: stseng@ocularsurface.com

*These two authors contributed equally to this work.

The part of this work was presented at the Annual Meeting of the Association of Research in Vision and Ophthalmology in Ft. Lauderdale, FL, USA on 1 May 2011. Received 21 July 2011; revised 23 October 2011; accepted 21 November 2011
} 
or contingent upon the presence of growth factors. If it is the latter, it remains unclear which growth factor(s) is responsible.

Disruption of cell junction appears critical to lead to EMT accompanied by proliferation and migration in the periphery of porcine RPE explants, where cadherin expression is predominantly $\mathrm{N}$-cadherin, but not in the center, where $\mathrm{N}$ - and P-cadherins are equally expressed. ${ }^{4}$ In many types of epithelial cells, transforming growth factor- $\beta$ (TGF- $\beta$ ) promotes EMT, but inhibits proliferation (reviewed by Huang and Huang ${ }^{9}$ ). Addition of TGF- $\beta 2$ in the above explant culture promotes expression of $\alpha$-SMA, while the fate of proliferation is unexplored. ${ }^{4}$ EMT also occurs in immediately confluent ARPE-19 cells in response to epidermal growth factor (EGF) ${ }^{10}$ TGF- $\beta,{ }^{10-12}$ or in combination ${ }^{10}$ without knowing whether these confluent ARPE-19 cells have ceased proliferation owing to contact inhibition. Thus, it remains unclear whether EMT with proliferation of the above instances depends on the addition of these growth factors or not, and if so, whether there are different responses among different growth factors.

Concerning the signaling pathway, TGF- $\beta$ promotes EMT via both Smad and non-Smad signaling and crosstalks between them (reviewed by Heldin et $a l^{13}$ ). Downstream to TGF- $\beta$ signaling includes ZEB1 and ZEB2, which are critical transcription factors repressing epithelial gene expression to trigger EMT. ${ }^{14,15}$ Interestingly, overexpression of ZEB1 in primary mouse RPE cultures leads to EMT with proliferation, ${ }^{16}$ which contradicts the notion that TGF- $\beta$ inhibits proliferation if ZEB1 overexpression simulates TGF- $\beta$ action. Alternatively, there exist other signaling pathways that are not mediated by TGF- $\beta$ to trigger EMT with proliferation. One possible candidate is the Hippo signaling pathway that governs the organ size by controlling contact inhibition and EMT (reviewed by Zeng and Hong ${ }^{17}$ ). In fact, knockdown of YAP and TAZ, two important mediators of Hippo signaling, leads to nuclear translocation of TAZ-TEAD1 coinciding with the loss of cell-cell contacts and ZEB1 nuclear expression, EMT, and proliferation in primary mouse RPE cultures. ${ }^{16}$

To clarify the above issues, we established an experimental model in which ARPE-19 cells exhibited contact inhibition after a period of post-confluence. Using this model, we discovered that the mitotic block mediated by contact inhibition can be unlocked by disruption of cell junctions with EGTA only in the presence of EGF and/or fibroblast growth factor-2 (FGF-2), but not TGF- $\beta 1$. Proliferation induced by EGTA + EGF + FGF-2 is caused by activation of the canonical Wnt signaling, but not by inhibition of the Hippo signaling. In contrast, EGTA + TGF- $\beta 1$ suppresses proliferation and Wnt signaling. The canonical Wnt signaling triggered by EGF + FGF- 2 is sufficient and synergized with TGF- $\beta 1$ in activating Smad/ZEB signaling responsible for EMT. These findings highlight the importance of the Wnt signaling activated by EGF + FGF-2 to unlock contact inhibition to initiate an early phase of EMT with proliferation, and establish a framework for future dissection of such pathogenic EMT in proliferative vitreoretinopathy.

\section{MATERIALS AND METHODS Antibodies and Reagents}

Dulbecco's modified Eagle's medium (DMEM), Ham's/F12 medium, human EGF, HEPES buffer, phosphate-buffered saline (PBS), amphotericin $B$, gentamicin, fetal bovine serum (FBS) and Alexa Fluor-conjugated secondary IgG were purchased from Invitrogen (Carlsbad, CA, USA). FGF-2, TGF$\beta 1$, bovine serum albumin, paraformaldehyde, methanol, Triton X-100, XAV939 (tankyrase I inhibitor) and Hoechst 33342 dye were purchased from Sigma (St Louis, MO, USA). Specific monoclonal antibodies (against $\alpha$-tubulin, $\alpha$-SMA, $\beta$-catenin, BrdU, N-cadherin, Na, K-ATPase, $\mathrm{p}$-Smad2/3, RPE65, TAZ, and vimentin) and polyclonal antibodies (against $\alpha$-catenin, connexin-43, histone, p120-catenin, p-TAZ, p-YAP, S100A4, TAZ, YAP, ZEB1, ZEB2, and ZO-1) were purchased from Abcam (La Jolla, CA, USA), BD Biosciences (San Jose, CA, USA), Cell Signaling Technology (Danvers, MA, USA), Chemicon (Temecula, CA, USA), Upstate (Billerica, MA, USA), Santa Cruz Biotechnology (Santa Cruz, CA, USA), Sigma, and Zymed (Carlsbad, CA, USA) (Supplementary Table 1). Both control and stable S33Y $\beta$-catenin plasmids were a gift from Dr Jan-Kan Chen (The Chang Gung University, Taiwan, ROC). ${ }^{18}$

\section{Cell Culture and Treatments}

All experiments were performed using ARPE-19, a human diploid RPE cell line (ATCC, Manassas, VA, USA) cultured in 24-well containing $250 \mu \mathrm{l}$ of HEPES-buffered DMEM and Ham's F-12 (1:1) supplemented with 10\% FBS, $2 \mathrm{mM}$ L-glutamine, $50 \mu \mathrm{g} / \mathrm{ml}$ gentamicin, and $1.25 \mu \mathrm{g} / \mathrm{ml}$ amphotericin $\mathrm{B}$ at $37^{\circ} \mathrm{C}$ in humidified air with $5 \% \mathrm{CO}_{2}$. Upon $100 \%$ confluence, cells were continuously cultured for 7 days before being tested. For cultures receiving transfection, $0.2 \mu \mathrm{g}$ of the control plasmid or the S33Y $\beta$-catenin plasmid was mixed with $3 \mu$ of SuperFect transfection reagent (Qiagen, Valencia, CA, USA) and $50 \mu \mathrm{l}$ of a serum-free DMEM/F12 medium for $30 \mathrm{~min}$ before being added drop wise to the culture and incubated for 1 day. For cultures not receiving transfection, cells were treated with or without $1 \mathrm{mM}$ EGTA, $10 \mathrm{ng} / \mathrm{ml}$ EGF, $20 \mathrm{ng} / \mathrm{ml} \mathrm{FGF-2,} 10 \mathrm{ng} / \mathrm{ml}$ TGF- $\beta 1$, or a combination of the above growth factor with or without $5 \mathrm{ng} / \mathrm{ml}$ XAV939, which is a specific antagonist of Wnt signaling ${ }^{19}$ singly or in combination. The proliferative status was assessed by the addition of BrdU to a final concentration of $10 \mu \mathrm{M}$ in the culture medium for $4 \mathrm{~h}$ before termination.

\section{Immunofluorescence Confocal Microscopy}

ARPE monolayer cultures were air-dried and fixed in $4 \%$

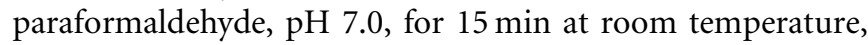
rehydrated in PBS, incubated with $0.2 \%$ Triton X-100 for $15 \mathrm{~min}$, and rinsed three times with PBS for 5 min each. After 
incubation with $2 \%$ BSA to block nonspecific staining for $30 \mathrm{~min}$, they were incubated with appropriate primary antibodies, of which dilutions are provided in Supplementary Table 1 , for $16 \mathrm{~h}$ at $4^{\circ} \mathrm{C}$. After three washes with PBS, they were incubated with corresponding Alexa Fluor-conjugated secondary $\operatorname{IgG}$ for $60 \mathrm{~min}$. For BrdU staining and nuclear localization staining of p120, samples were fixed with $75 \%$ methanol plus $25 \%$ acetic acid for $15 \mathrm{~min}$, denatured by $2 \mathrm{M}$ $\mathrm{HCl}$ for $30 \mathrm{~min}$ at $37^{\circ} \mathrm{C}$ and neutralized by $0.1 \mathrm{M}$ borate buffer, $\mathrm{pH}$ 8.5, for $5 \mathrm{~min}$ three times. Monoclonal anti-BrdU and polyclonal anti-p120 antibodies and Alexa Fluor-conjugated secondary IgGs were used for immunostaining of BrdU- and p120-positive nuclei. The samples were then counterstained with Hoechst 33342 and analyzed with Zeiss LSM 700 confocal microscope (Thornhood, NY, USA). Corresponding mouse and rabbit sera were used as negative controls for primary monoclonal and polyclonal antibodies, respectively. The BrdU labeling index (\%) was measured by counting BrdU-positive cells among total cells in three different fields and expressed as mean \pm s.e.m.

\section{Preparation of Cell Lysates}

To prepare protein extracts from the membrane, cytosol, and nucleus, we followed Qproteome Cell Compartment protocol (Qiagen). Briefly, cells were first added with Extraction Buffer CE1, which selectively disrupts but without solubilizing the plasma membrane, resulting in isolation of cytosolic proteins, followed by centrifugation at $100 \mathrm{~g}$ for $10 \mathrm{~min}$ to pellet plasma membranes and compartmentalized organelles, such as the nuclei, mitochondria, and endoplasmic reticulum. The pellet was then resuspended in Extraction Buffer CE2, which solubilizes the plasma membrane as well as all organelle membranes except the nuclear membrane, followed by centrifugation at $6000 \mathrm{~g}$ for $10 \mathrm{~min}$ to pellet the nuclei. The supernatant contains membrane proteins and proteins from the endoplasmic reticulum and mitochondria. Finally, the pellet containing the nuclei was solubilized using Extraction Buffer CE3, in which all soluble and most membrane-bound nuclear proteins are extracted, and then pelleted by centrifugation at $6800 \mathrm{~g}$ for $10 \mathrm{~min}$.

\section{Immunoprecipitation and Western Blotting}

To determine interaction between $\beta$-catenin and LEF-1, the nuclear protein extracts were first immunoprecipitated with an anti- $\beta$-catenin antibody. The immunoprecipitates and other protein extracts from the above three compartments were electrophoresized on 4-15\% (w/v) gradient acrylamide ready gels (Bio-Rad, Hercules, CA, USA) under denaturing and reducing conditions, and transferred to a nitrocellulose membrane (Bio-Rad), which was then blocked with $5 \%(\mathrm{w} / \mathrm{v})$ fat-free milk powder in Tris-buffered saline $(10 \mathrm{mM}$ Tris $\mathrm{HCl}$ ( $\mathrm{pH}$ 7.4) and $150 \mathrm{mM} \mathrm{NaCl}$ (TBS) $)+0.05 \%$ Tween- 20 (TBST) for $1 \mathrm{~h}$ at room temperature, and washed three times for $10 \mathrm{~min}$ with TBST. After overnight incubation at $4{ }^{\circ} \mathrm{C}$ with specific primary antibodies against $\beta$-catenin, LEF1,
p-Smad2/3, ZEB1, and ZEB2, and washed three times for $10 \mathrm{~min}$ with TBST, the membranes were incubated for $1 \mathrm{~h}$ with horseradish peroxidase-conjugated secondary antibodies diluted in TBST using $\mathrm{Cx} 43, \alpha$-tubulin, and histone as the loading control for the membranous, cytosolic, and nuclear compartments, respectively. Then, membranes were washed twice for $10 \mathrm{~min}$ with TBST and once for $5 \mathrm{~min}$ with TBS, and then immunoreactive proteins were detected with Western Lighting Chemiluminescence Reagent (PerkinElmer, Waltham, MA, USA). Densitometry analysis was performed with computer software (Image); National Institutes of Health, Bethesda, MD, USA).

\section{TCF/LEF Reporter Assay}

To determine the Wnt signalling, the assay was performed by co-transfecting ARPE monolayers with $0.4 \%(\mathrm{w} / \mathrm{v})$ of the TCF/LEF reporter construct that harbors TCF/LEF promoter sequence (SABiosciences, Frederick, MD, USA) or its corresponding control plasmid and $0.01 \%(\mathrm{w} / \mathrm{v})$ of pRL-TK internal control plasmids with $1 \%(\mathrm{w} / \mathrm{v})$ SuperFect plasmid transfection reagent in the aforementioned medium for $24 \mathrm{~h}$ before adding various treatments in the fresh medium. Cell lysates were assayed for firefly luciferase and Renilla luciferase activities using a Dual-Luciferase Reporter Assay System (Promega, Madison, WI, USA) and TD-20/20 luminometer (Turner BioSystems, Sunnyvale, CA, USA). The ratio of firefly luciferase and Renilla luciferase activities was used to determine whether the promoters are activated.

\section{Statistics}

All data are presented as blots or images from at least three similar experiments or as mean \pm s.d. for the number of experiments $(n)$ indicated. Statistical significance was determined by Student's unpaired $t$-test or one-way ANOVA using Microsoft Excel (Microsoft, Redmont, WA, USA), where $P<0.05$ was considered statistically significant.

\section{RESULTS \\ Contact Inhibition Prevails in Post-Confluent ARPE-19 Cells When Cell Junctions Mature to an In Vivo Pattern} We first would like to establish the culturing model of ARPE19 cells to ensure that contact inhibition occurred when cell junctions matured. ARPE-19 cells were cultured for 2 days before confluence, that is, $25 \%$ confluence, and various times post-confluence. The proliferative status assessed by the BrdU labeling remained active even on day 4 post-confluence, but became abruptly negative from day 7 onwards post-confluence (Figure 1a). Both RT-PCR and western blot analyses confirmed the expression of adherent and tight junction components, such as $\mathrm{N}$-cadherin, $\alpha$-catenin, $\beta$-catenin, p120catenin, and ZO-1 by ARPE-19 cells before and after confluence (not shown). Cytolocalization of these components was then determined by immunostaining. The result showed a predominant cytoplasmic staining pattern 2 days before confluence (Figure 1b), but a predominant junctional 


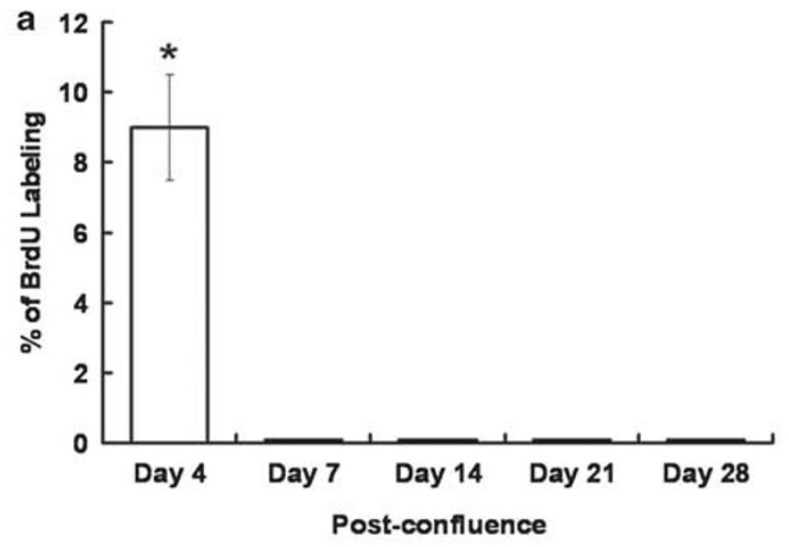

b
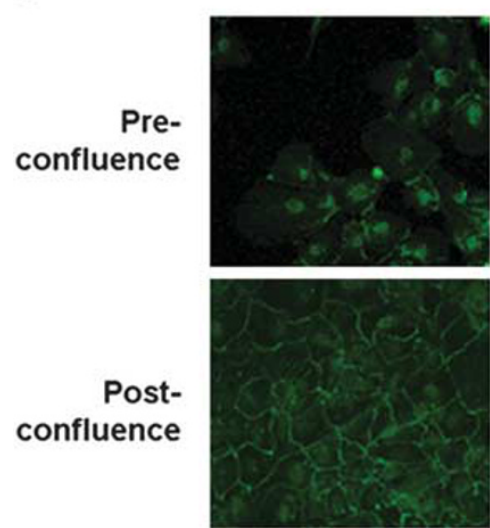

$\alpha$-catenin
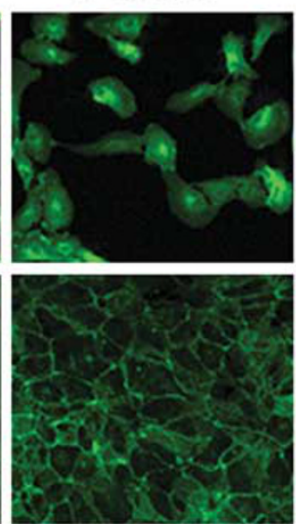

$\beta$-catenin
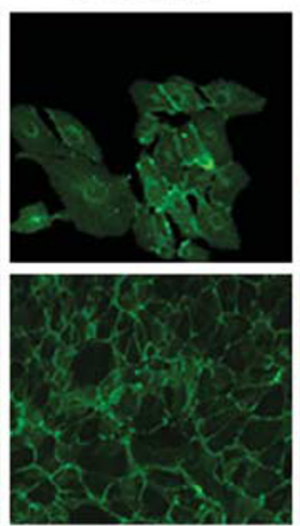

p120-catenin
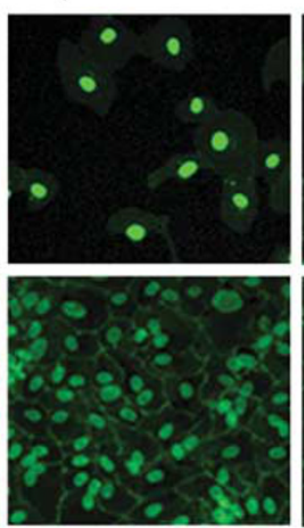

ZO-1
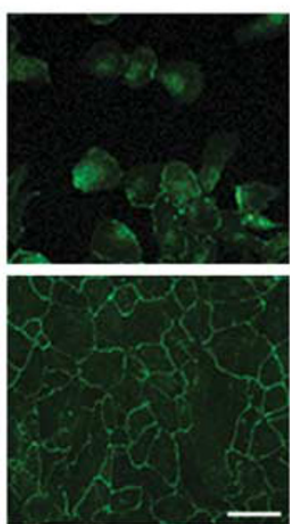

Figure 1 Maturation of cell junctions coincides with contact inhibition in post-confluent ARPE-19 cells. (a) Proliferation assessed by bromodeoxyuridine (BrdU) labeling was still positive on day 4 post-confluence, but became abruptly negative from day 7 post-confluence $\left({ }^{*} P<0.05\right)$. (b) Immunostaining of adherent junction components such as $\mathrm{N}$-cadherin, $\alpha$-catenin, $\beta$-catenin, and p120 catenin, and tight junction component such as ZO- 1 was performed in cells at $25 \%$ confluence (pre-confluence) and 10 days post-confluence. All components moved from the cytoplasm to the intercellular membrane. Scale bar, $100 \mu \mathrm{m}$.

staining pattern when cells were cultured up to 7 days postconfluence (Figure 1b). P120-catenin was also found in the nucleus. These results confirmed that contact inhibition coincided with maturation of cell junctions in ARPE-19 cells. We therefore chose day 7 post-confluence for the remaining experiments.

\section{Proliferation in Contact-Inhibited ARPE-19 Cells Is Enhanced by EGTA only with EGF and/or FGF-2, but Inhibited by TGF- $\beta 1$}

To test if cell junction perturbation is critical to unlocking contact inhibition, BrdU incorporation was performed in ARPE-19 cells cultured to 7 days post-confluence. Without EGTA, no BrdU labeling was detected even if different growth factors, such as EGF, FGF-2, EGF + FGF-2, or TGF- $\beta 1$, were added for 1 day (Figure 2a), suggesting that contact inhibition could not be unlocked if cell junctions remained intact. In contrast, when cell junctions were perturbed by EGTA for 1 day, BrdU labeling was detected if EGF, FGF-2, or EGF + FGF-2 was added for 1 day (Figure 2a), with additive effect noted between EGF and FGF-2 $(n=6, P<0.05)$. As a comparison, BrdU labeling was not promoted by TGF- $\beta 1$, suggesting that TGF- $\beta 1$ antagonizes FGF- and EGF-stimulated cell proliferation (Figure $2 \mathrm{~b}$ ). Under phase-contrast microscopy, cell morphology or junction was not significantly altered by EGTA with or without growth factors (not shown).

\section{EMT Occurs in Contact-Inhibited ARPE-19 Cells Treated by EGTA with EGF + FGF-2 with or without TGF- $\beta 1$}

Given that contact inhibition was unlocked by EGTA plus growth factor, we wondered if phenotype of ARPE-19 cells was altered or not. Besides $\mathrm{N}$-cadherin ${ }^{3,20}$ and $\mathrm{ZO}-1,{ }^{21}$ we noted that RPE65, a key enzyme within the visual cycle and also a differentiation marker of RPE cells, ${ }^{1}$ and Na, K-ATPase $^{22}$ were also expressed by post-confluent ARPE-19 cells in the intercellular junctions (Figure 3a). EGTA alone could not, but EGTA followed by the addition of EGF + FGF-2 clearly dissolved their staining in the intercellular junction, with a lesser extent by TGF- $\beta 1$ or EGF + FGF- 2 + TGF- $\beta 1$. To determine if the loss of normal RPE phenotype was coupled with EMT, we studied the expression of vimentin, S100A4, 
a
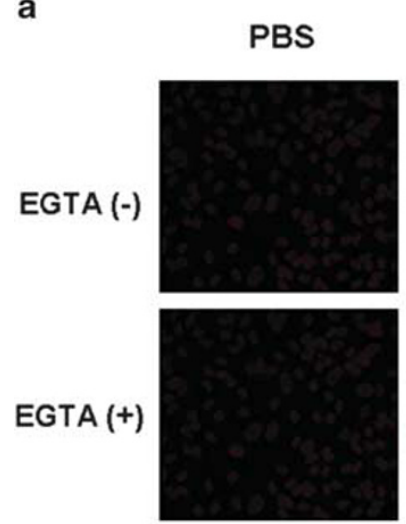

EGF
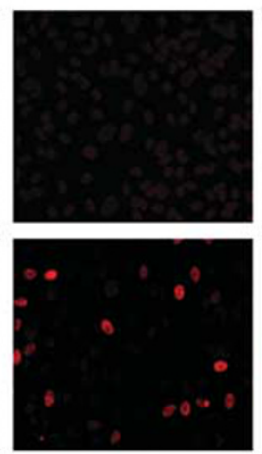

FGF-2
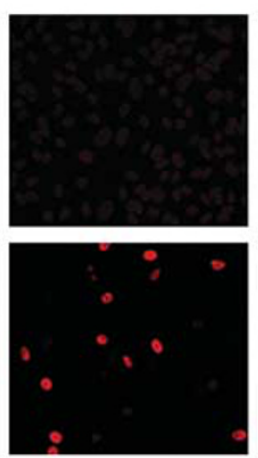

TGF- $\beta 1$
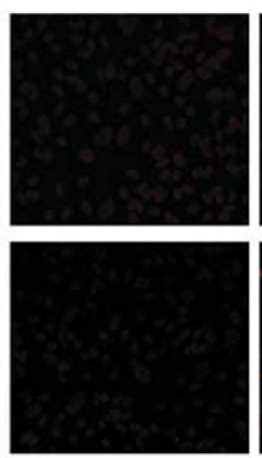

$E G F+F G F-2$
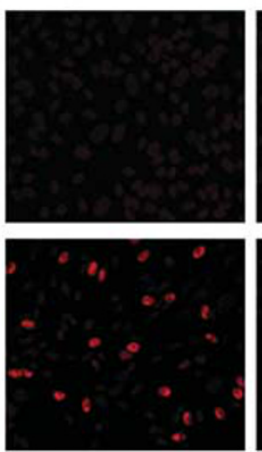

EGF+FGF2 + TGF- $\beta 1$
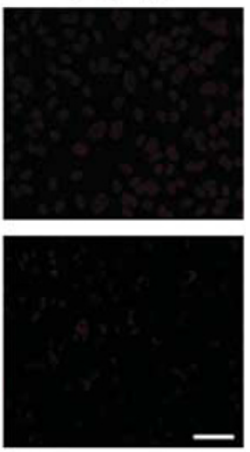

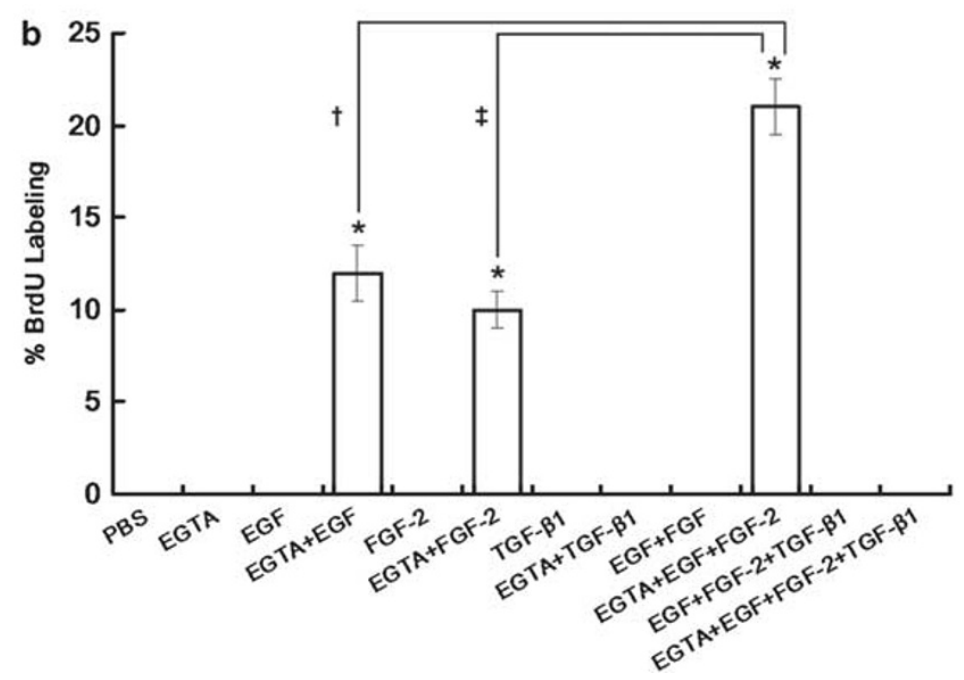

Figure 2 Contact inhibition is unlocked by ethylene glycol tetraacetic acid (EGTA) only in the presence of epidermal growth factor (EGF) and/or fibroblast growth factor-2 (FGF-2), but not transforming growth factor- $\beta 1$ (TGF- $\beta 1$ ). (a) Immunostaining of bromodeoxyuridine (BrdU) was performed in ARPE-19 cells cultured to day 7 post-confluence after being treated without or with $1 \mathrm{mg} / \mathrm{ml} \mathrm{EGTA}$, immediately followed by PBS, $10 \mathrm{ng} / \mathrm{ml}$ EGF, $20 \mathrm{ng} / \mathrm{ml} \mathrm{FGF-2,} 10 \mathrm{ng} / \mathrm{ml} \mathrm{TGF}-\beta 1,10 \mathrm{ng} / \mathrm{ml} \mathrm{EGF}+20 \mathrm{ng} / \mathrm{ml} \mathrm{FGF-2,} \mathrm{or} 10 \mathrm{ng} / \mathrm{ml} \mathrm{EGF}+20 \mathrm{ng} / \mathrm{ml} \mathrm{FGF-2}+10 \mathrm{ng} / \mathrm{ml}$ TGF- $\beta 1$ for 1 day. Without EGTA, no BrdU labeling was found. When EGTA was added, BrdU labeling was promoted by EGF, FGF-2, or EGF + FGF-2, but not by PBS, TGF- $\beta 1$, or EGF + FGF-2 + TGF- $\beta 1$. Scale bar, $100 \mu \mathrm{m}$. (b) The BrdU labeling index was significantly increased by EGF, FGF-2, or in combination (highest) when EGTA was added $\left(*{ }^{\dagger}\right.$ and $\left.{ }^{\ddagger} P<0.05\right)$.

and $\alpha$-SMA as a gain of a mesenchymal phenotype (reviewed by Zeisberg and Neilson ${ }^{23}$ and Schneider $e a^{24}$ ). Our results showed that expression of all three mesenchymal markers was either weak (vimentin) or negative (S100A4 and $\alpha$-SMA) in post-confluent ARPE-19 cells (Figure 3a). Following EGTA treatment, expressions of both vimentin and $\alpha$-SMA were enhanced by TGF- $\beta 1$, EGF + FGF-2, or EGF + FGF- $2+$ TGF- $\beta 1$, while that of S100A4 was not only enhanced by EGF + FGF-2, but also by TGF- $\beta 1$. These results collectively indicated that contact inhibition unlocked by EGTA with EGF + FGF-2 was accompanied by the loss of normal RPE phenotype and a gain of a mesenchymal phenotype suggestive of EMT.

EMT with Proliferation Induced by EGTA + EGF + FGF-2 Is Linked with Wnt/ $\beta$-Catenin, but not Hippo Pathway

Because S100A4 has previously been shown to be a transcriptional target of the canonical Wnt/ $\beta$-catenin signaling pathway, ${ }^{25}$ which can be interceded by the Hippo pathway, ${ }^{26,27}$ we next examined if both signaling pathways were involved in our model system. When contact inhibition was not disrupted by EGTA, neither cytoplasmic expression of p-TAZ or p-YAP nor nuclear expression of TAZ or YAP was detected. This staining pattern was not change even if cells were treated with EGTA + EGF, FGF-2, EGF + FGF-2, or TGF- $\beta 1$ for 1 day (not shown), implying that the Hippo pathway was not involved in unlocking contact inhibition by the above growth factors or subsequent EMT. In contrast, when contact inhibition was not disrupted by EGTA, addition of EGF + FGF-2 did not enhance LEF-1 mRNA expression or cause nuclear staining of $\beta$-catenin and LEF1 and cytoplasmic staining of $\alpha$-SMA (not shown). However, following EGTA treatment, addition of EGF + FGF-2 enhanced twofold LEF-1 mRNA expression (not shown) and nuclear staining of $\beta$-catenin translocated from the membrane and nuclear staining of LEF1 (Figure 4a). Western blot 
a

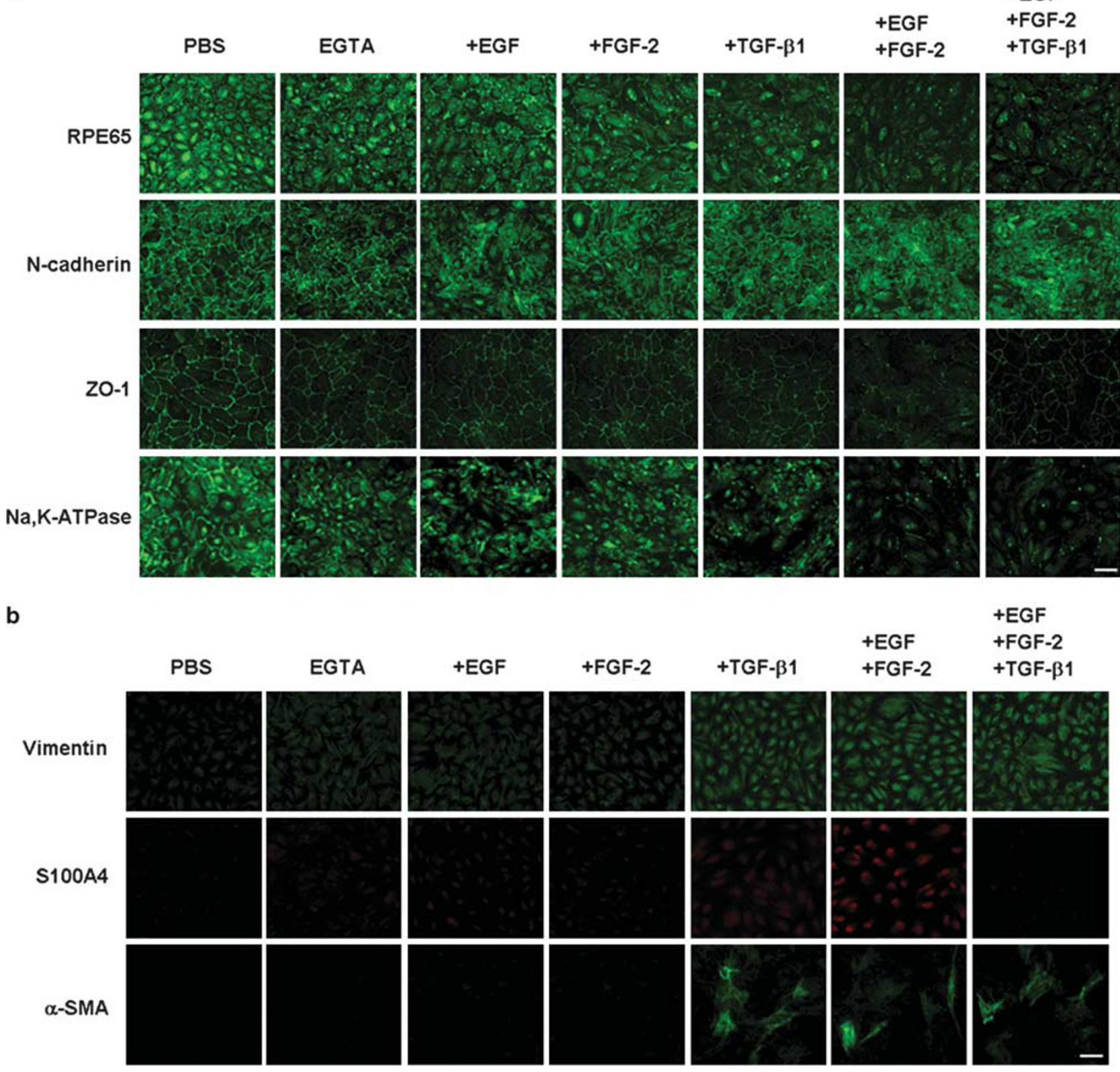

Figure 3 Epithelial-mesenchymal transition (EMT) occurs only when the junction is disrupted by ethylene glycol tetraacetic acid (EGTA) in the presence of epidermal growth factor + fibroblast growth factor-2 (EGF + FGF-2) with or without transforming growth factor- $\beta 1$ (TGF- $\beta 1$ ). (a) Immunostaining showed marked dissolution of junctional staining of RPE65, N-cadherin, ZO-1, and Na,K-ATPase by EGF + FGF-2 with or without TGF- $\beta 1$ and to a lesser extent by EGF, FGF-2, or TGF- $\beta 1$ alone. No effect was noted in EGTA alone. (b) The immunostaining with vimentin (upper panel) was positive in all, but most obvious in cells treated with TGF- $\beta 1$, EGF + FGF-2, or EGF + FGF- $2+$ TGF- $\beta 1$. The immunostaining with S100A4 (middle panel) was only obviously positive in cells treated with EGF + FGF-2. The immunostaining with $\alpha$-smooth muscle actin ( $\alpha$-SMA) (lower panel) was most pronounced in cells treated with TGF- $\beta 1$, EGF + FGF-2, and EGF + FGF-2 + TGF- $\beta 1$. EGTA alone had no effect. Scale bar, $100 \mu$ m.

further confirmed increased nuclear contents of $\beta$-catenin and LEF1, but decreased membranous contents of $\beta$-catenin in cells treated with EGF + FGF-2 (Figure $4 \mathrm{~b}$ ). To confirm that activation of $\mathrm{Wnt} / \beta$-catenin was sufficient to cause proliferation and EMT, we performed overexpression of S33Y $\beta$-catenin in post-confluent ARPE treated with EGTA, but without growth factors, and showed an increase of BrdU labeling, nuclear $\beta$-catenin and S100A4, and cytoplasmic $\alpha$-SMA (Figure $4 \mathrm{c}$ ). We also performed immunoprecipitation of the nuclear extracts with an anti- $\beta$-catenin antibody, followed by western blotting with an anti-LEF-1 antibody. The result confirmed the tight association between $\beta$-catenin and LEF-1 in the nucleus, further confirming activation of the Wnt signaling (Figure $4 \mathrm{~d}$ ). These results suggested that the 


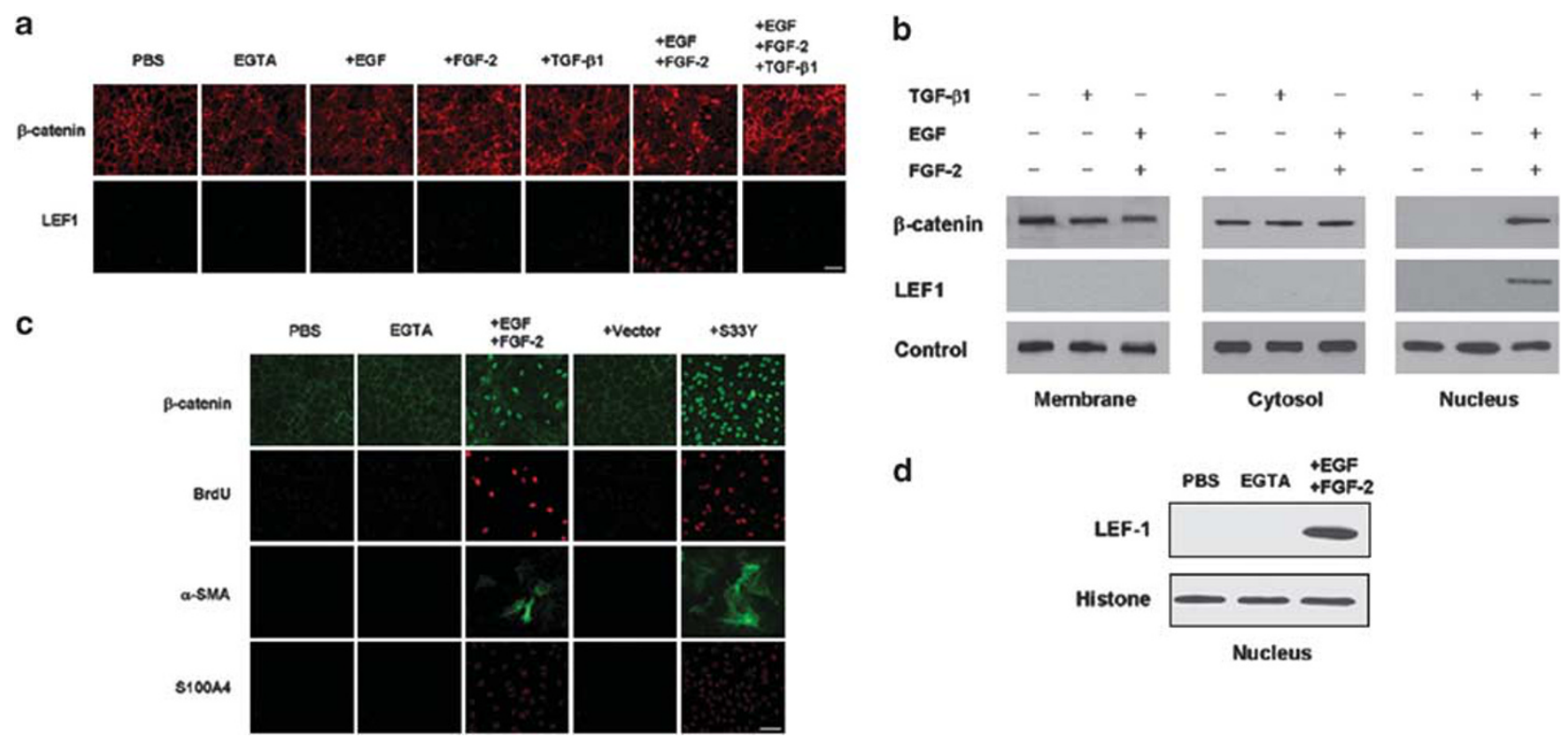

Figure 4 Ethylene glycol tetraacetic acid + epidermal growth factor + fibroblast growth factor-2 (EGTA + EGF + FGF-2) activates Wnt/ $\beta$-catenin signaling. (a) Immunostaining revealed nuclear $\beta$-catenin and LEF1 only when cells were treated with EGTA + EGF + FGF-2, but not EGTA alone. Scale bar, $100 \mu \mathrm{m}$ (b) Western blot analysis confirmed increased nuclear contents of $\beta$-catenin and LEF1 in the nuclear extract, but decreased $\beta$-catenin in the membranous extract when cells were treated by EGTA with EGF + FGF-2. Levels of connexin $43, \alpha$-tubulin, and histone were used as loading controls for membranous, cytosolic, and nuclear extracts, respectively. (c) Overexpression of S33Y $\beta$-catenin in post-confluent ARPE treated with EGTA without growth factors increased bromodeoxyuridine (BrdU) labeling, nuclear $\beta$-catenin and S100A4, and cytoplasmic $\alpha$-smooth muscle actin ( $\alpha$-SMA). (d) Immunoprecipitation by anti- $\beta$-catenin antibody followed by western blotting with anti-LEF-1 antibody confirmed tight association between $\beta$-catenin and LEF-1 in the nuclear extract from EGTA + EGF + FGF-2, but not from phosphate-buffered saline (PBS) or EGTA alone.

mitotic block unlocked by EGTA + EGF + FGF-2 was indeed associated with activation of $\mathrm{Wnt} / \beta$-catenin, but not with suppression of Hippo signaling pathway.

EMT with Proliferation Induced by EGTA + EGF + FGF-2 Is Blocked by Wnt Inhibitor (XAV939), but Rescued by Overexpression of Stable S33Y $\beta$-Catenin

To confirm that $\mathrm{Wnt} / \beta$-catenin signaling pathway was responsible for the EMT with proliferation induced by EGF + FGF-2, we transfected post-confluent ARPE-19 cells with a plasmid containing TCF/LEF promoter construct and simultaneously treated the cells with XAV939, a specific Wnt inhibitor, which promotes the phosphorylation-dependent degradation of $\beta$-catenin by increasing the activity of the destruction complex. ${ }^{19}$ The promoter activity was low in PBS with or without EGTA even after EGF or FGF-2 was added, but elevated 15-fold in EGTA with EGF + FGF-2 (Figure 5a), suggesting that Wnt signaling was activated only when EGF was added together with FGF-2 following EGTA to perturb cell junctions. Such an elevated promoter activity was completely suppressed by XAV939 $(n=3, P<0.05)$. TGF- $\beta 1$ alone did not activate the TCF/LEF promoter activity. In fact, TGF- $\beta 1$ also suppressed the TCF/LEF promoter activity promoted by EGF + FGF-2. Consequently, the BrdU labeling reverted to the baseline quiescence followed by XAV931S100A4, and $\alpha$-SMA was either diminished or abolished, while the nuclear staining of $\beta$-catenin was reverted to membranous staining or that of LEF1 was suppressed (Figure 5c). Such inhibition of proliferation and EMT by XAV939 could be rescued by overexpression of stable S33Y $\beta$-catenin only when cells were treated with EGTA followed by EGF + FGF-2 (Figure 5d). These results collectively indicated that $\mathrm{Wnt} / \beta$-catenin signaling causatively controlled EMT with proliferation caused by EGF + FGF- 2 when cell junctions were disrupted by EGTA.

\section{EGF + FGF-2 Is Sufficient and Synergized with TGF- $\beta 1$ in Activating Smad/ZEB Signaling}

EGTA treatment followed by TGF- $\beta 1$ or EGF + FGF$2+$ TGF- $\beta 1$ induced EMT (Figure 3), but suppressed proliferation (Figure 2), suggesting that EGTA + EGF + FGF-2 could not promote proliferation in the presence of TGF- $\beta 1$. Because the canonical Wnt signaling induced by EG$\mathrm{TA}+\mathrm{EGF}+\mathrm{FGF}-2$ was causatively linked to EMT with proliferation (Figures 4 and 5), we wondered whether EGF + FGF- 2 also triggered EMT, as did TGF- $\beta 1$. A number of studies have shown that EMT is induced by TGF- $\beta$ in a Smad-dependent manner (reviewed by Xu et $a^{28}$ ) via direct interaction of nuclear $\mathrm{p}-\mathrm{Smad} 2 / 3$ with the zinc-finger factors ZEB1 and ZEB2. ${ }^{14,15}$ We thus performed immunostaining of p-Smad2/3, ZEB1, and ZEB2 in post-confluent ARPE-19 cells treated with various growth factors following EGTA. Nuclear staining of p-Smad2/3, ZEB1, and ZEB2 was only found in cells treated with TGF- $\beta 1$, EGF + FGF-2, or EGF + FGF-2 
a

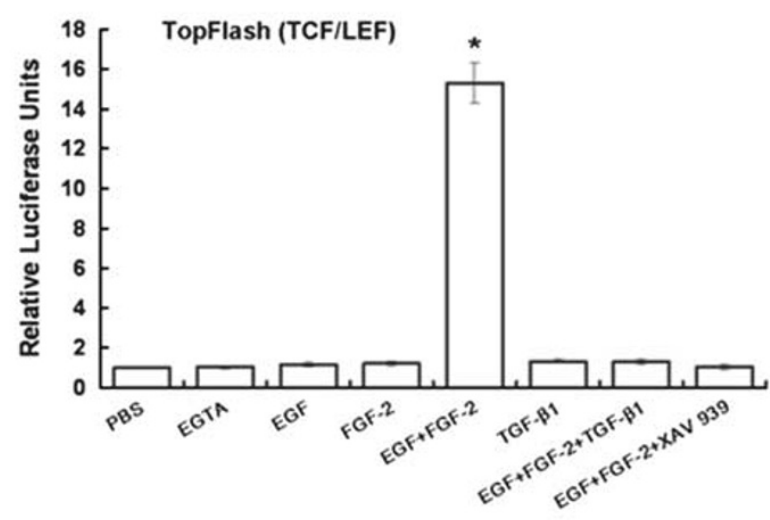

C

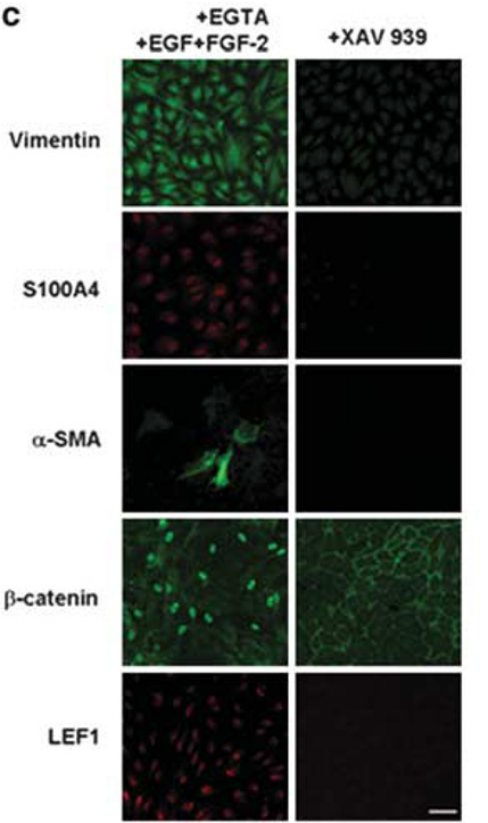

b
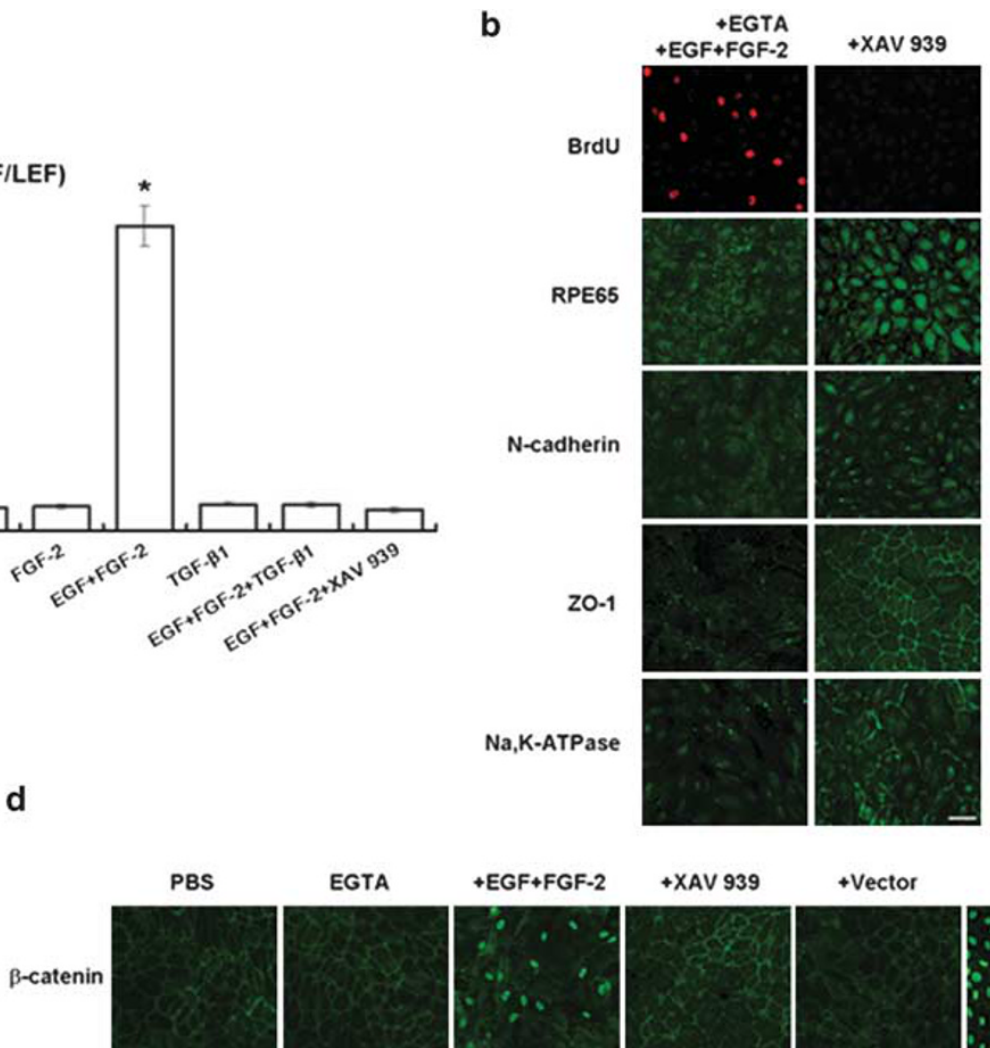
EGTA
$+E G F+F G F-2$
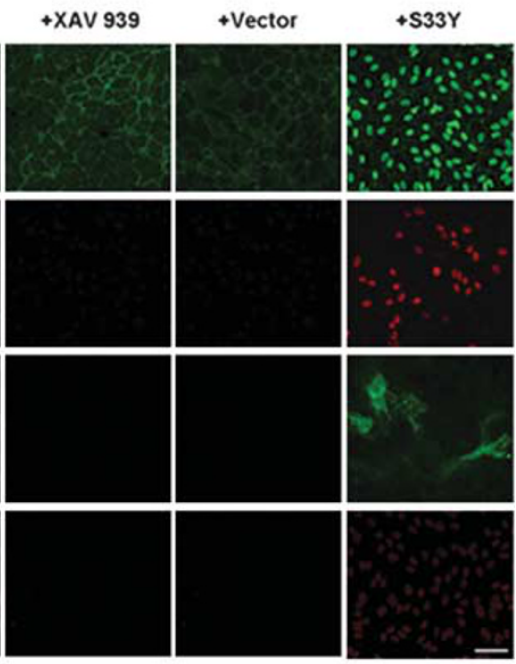

BrdU
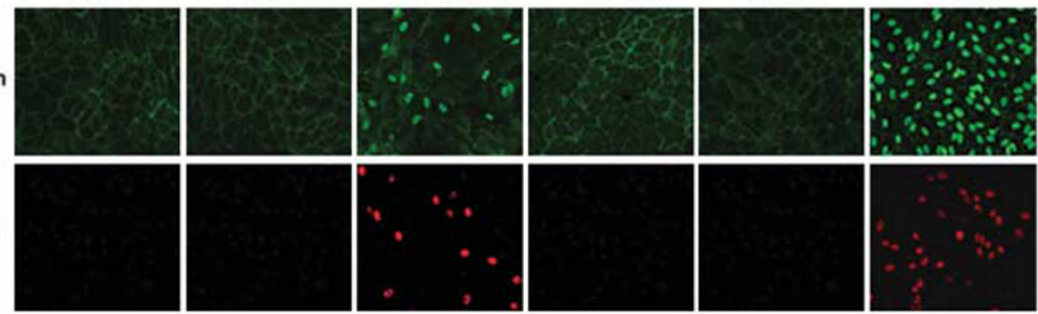

$\alpha$-SMA
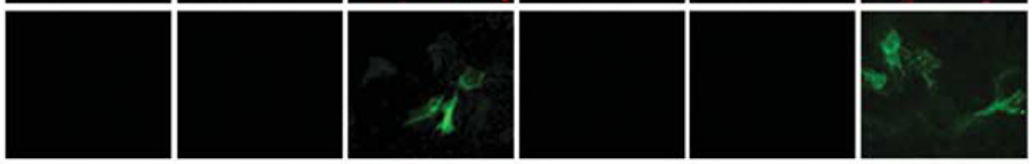

S100A4
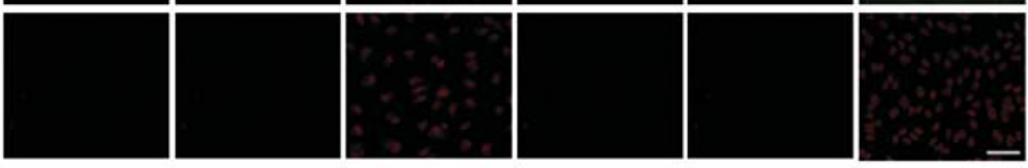

Figure 5 Epithelial-mesenchymal transition (EMT) with proliferation induced by ethylene glycol tetraacetic acid (EGTA) with epidermal growth factor + fibroblast growth factor-2 (EGF + FGF-2) is caused by Wnt/ $\beta$-catenin signaling by rescued by SS3Y $\beta$-catenin. (a) The TCF/LEF reporter activity was silent in cells treated by phosphate-buffered saline (PBS), EGTA, EGF, FGF-2, transforming growth factor- $\beta 1$ (TGF- $\beta 1$ ), or EGF + FGF- $2+$ TGF- $\beta 1$, but elevated 15 -fold by EGTA with EGF + FGF-2. The latter was abolished by XAV939 $\left({ }^{*} P<0.05\right)$. (b) Immunostaining revealed that XAV939 abolished nuclear staining of bromodeoxyuridine (BrdU), enhanced cytoplasmic staining of RPE65, and reverted the cytoplasmic staining pattern of N-cadherin, ZO-1, and $\mathrm{Na}, \mathrm{K}-\mathrm{ATPase}$ to the membranous staining pattern. (c) Immunostaining also revealed that XAV939 diminished the cytoplasmic staining of vimentin, reverted nuclear staining of $\beta$-catenin to the membranous staining, and abolished nuclear staining of S100A4 and LEF1, as well as cytoplasmic staining of $\alpha$-smooth muscle actin ( $\alpha$-SMA). (d) Inhibition of proliferation and EMT by XAV 939 was rescued by overexpression of stable SS3Y $\beta$-catenin, resulting in an increase of BrdU labeling, nuclear staining of $\beta$-catenin and S100A4, and cytoplasmic staining of $\alpha$-SMA. Scale bar, $100 \mu \mathrm{m}$.

+ TGF- $\beta 1$, but not EGTA alone (Figure 6a). Western blot analysis of the nuclear extract confirmed such an immunostaining finding that EGTA alone was not sufficient, while with EGF + FGF-2, it was indeed sufficient to elevate nuclear levels of p-Smad2/3, ZEB1 and ZEB2 (Figure 6b). Because the nuclear level of p-Smad2/3, ZEB1, or ZEB2 by
EGF + FGF- 2 and that by TGF- $\beta 1$ were less than that by EGF + FGF- 2 + TGF- $\beta 1$, there appeared to be an additive relationship (Figure $6 \mathrm{~b}$ and $\mathrm{c}$ ). We then added XAV939 to inhibit the Wnt signaling to see how it might be linked to Smad/ZEB1/2 signaling. Western blot analysis showed that XAV939 did not affect the nuclear level of pSmad2/3 in EGTA 
a

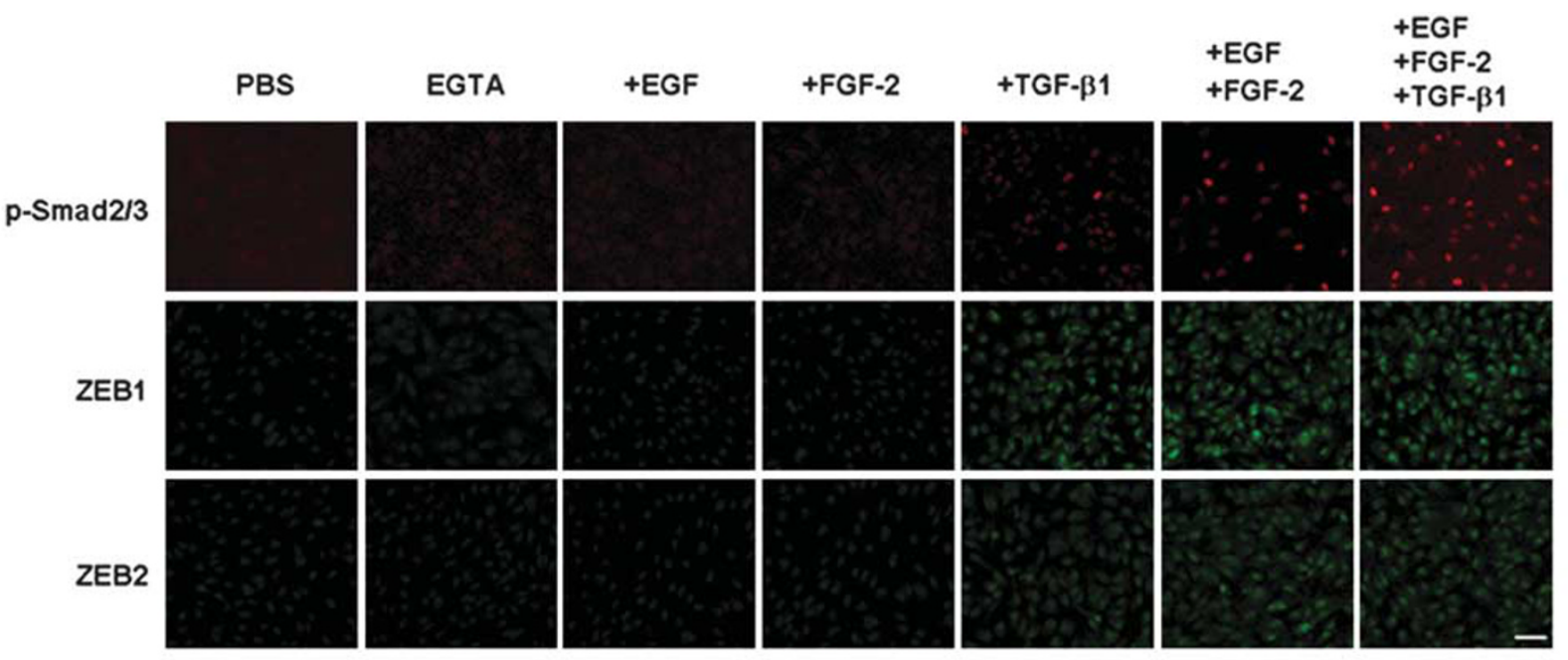

b
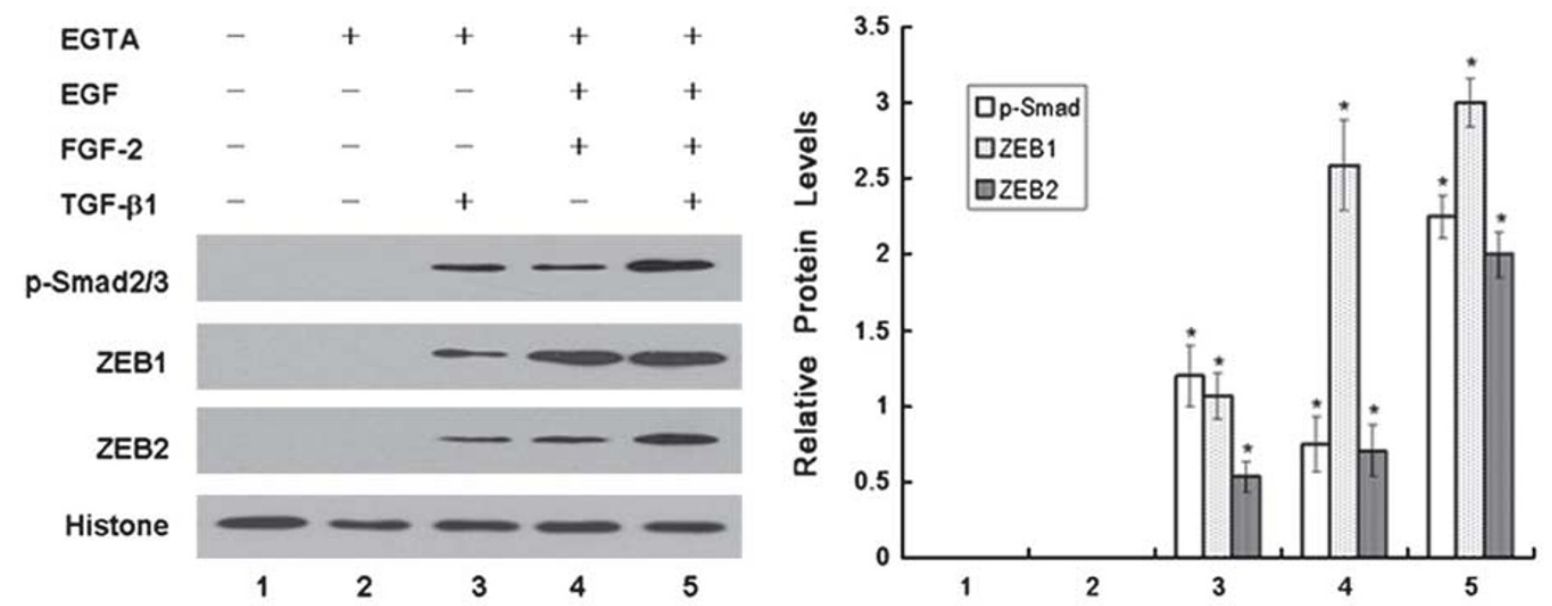

c
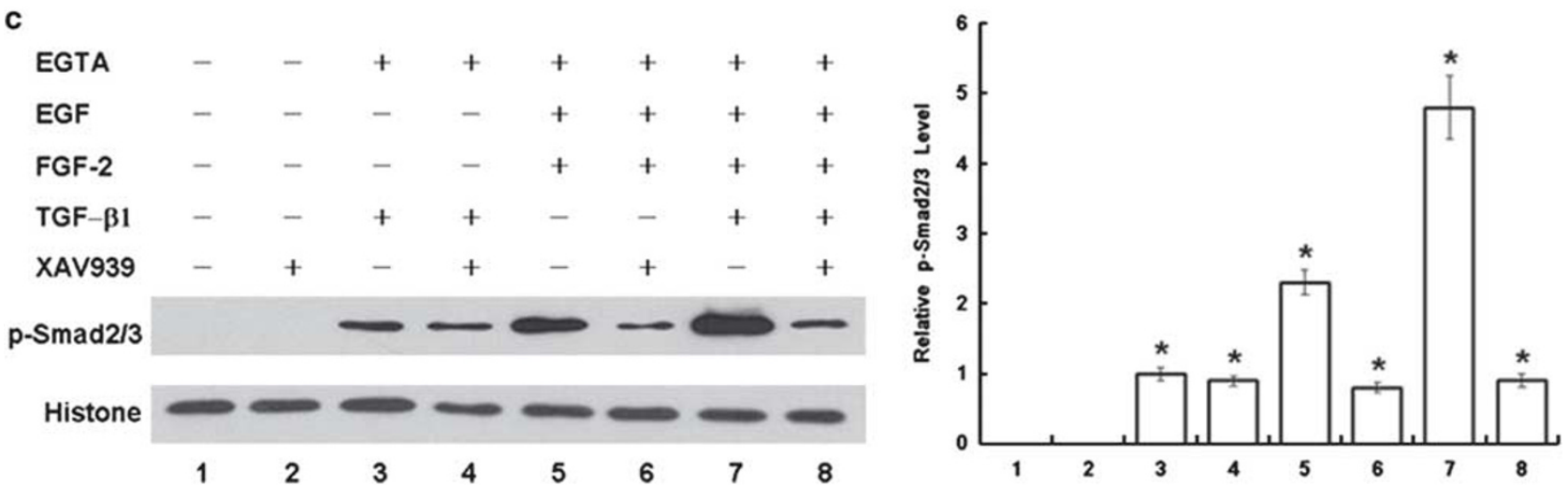

Figure 6 Wnt signaling by ethylene glycol tetraacetic acid + epidermal growth factor + fibroblast growth factor-2 (EGTA + EGF + FGF-2) is sufficient and additive with transforming growth factor- $\beta 1$ (TGF- $\beta 1$ ) to trigger Smad/ZEB1/2 signaling. (a) Immunostaining showed nuclear staining of p-Smad2/3 (upper panel), ZEB1 (middle panel), and ZEB2 (lower panel) in cells only treated by EGTA with TGF- $\beta 1$, EGF + FGF- 2 , or EGF + FGF-2 + TGF- $\beta 1$, but not EGTA alone. Scale bar, $100 \mu \mathrm{m}$. (b) Western blot analysis confirmed that the nuclear levels of p-Smad2/3, ZEB1, and ZEB2 were not activated by EGTA alone until TGF- $\beta 1$, EGF + FGF-2, or EGF + FGF-2 + TGF- $\beta 1$ was added with an additive action between the former two. (c) Western blot analysis also confirmed that the blocking of the Wnt signaling by XAV939 decreased the nuclear level of $p-S m a d 2 / 3$ only in cells treated with EGF + FGF-2, but not TGF- $\beta 1$. Histone was used as a loading control $\left({ }^{*} P<0.05\right)$. 
or TGF- $\beta 1$-treated cells, but reduced while not abolishing that in EGF + FGF-2-treated cells (Figure 6c), confirming that the Wnt signaling independently contributed to activation of Smad signaling. Furthermore, XAV939 also reduced the nuclear level of $\mathrm{pSmad} 2 / 3$ in $\mathrm{EGF}+\mathrm{FGF}-$ $2+$ TGF- $\beta 1$ to that of TGF- $\beta 1$ only. Taken together, EMT with or without proliferation induced by the above growth factors could occur only after cell junctions were perturbed by EGTA. EMT with proliferation was resulted from activation of canonical Wnt signaling, which by itself was sufficient to activate Smad/ZEB1/2 signaling. Activation of Smad/ ZEB1/2 signaling by TGF- $\beta 1$ triggered EMT without proliferation.

\section{DISCUSSION}

Our study showed that cessation of proliferation due to contact inhibition did not ensue until at least 7 days postconfluence (Figure 1). Although E-cadherin gene is constitutively expressed in RPE and ARPE-19 cells, its protein was not detected at any time point of our cultured ARPE-19 cells as reported previously. ${ }^{29}$ As a comparison, $\mathrm{N}$-cadherin was prevalent in RPE and post-confluent ARPE-19 cells. ${ }^{3,20}$ Post-confluent contact-inhibited ARPE-19 cells expressed membranous RPE65 (a microsomal protein), ZO-1, and $\mathrm{Na}$, K-ATPase (Figure 3a), indicative of maintenance of a normal RPE phenotype. Vimentin is expressed in fetal or cultured, but not adult, RPE cells (reviewed by Kivela and Uusitalo $\left.^{30}\right)$. Herein, we noted that vimentin was weakly expressed in post-confluent ARPE-19 cells (Figure 3b) similar to what has been reported. ${ }^{10}$ Using this in vitro model, we noted that contact inhibition disrupted by EGTA led to proliferation only in the presence of EGF and/or FGF-2, but not TGF- $\beta 1$. A previous study has shown that EGTA is required to disrupt contact inhibition to trigger proliferation only in the migrating cells in the periphery of porcine RPE explants without adding any growth factor. ${ }^{4}$ We wonder whether the lens capsule used for attaching porcine RPE explants might have released FGF-2 following EGTA treatment and whether migrating cells in the periphery might be more prone to undergo mitosis without growth factors. ${ }^{31}$ The finding that TGF- $\beta 1$ suppressed proliferation that was stimulated by EGF + FGF-2 (Figure 2a) was consistent with the general suppressive effect of TGF- $\beta 1$ on epithelial proliferation (reviewed by Huang and Huang ${ }^{9}$ and Moustakas et $a l^{32}$ ).

The mitotic block unlocked by EGTA + EGF + FGF-2 was mediated by activation of canonical Wnt signaling, a notion supported by nuclear staining of $\beta$-catenin, a significant increase of nuclear $\beta$-catenin and LEF1 protein levels, and close interaction between them (Figure 4). Further support came from the experiments showing that the aforementioned change correlated well with a significant increase of the TCF/ LEF promoter activity and that addition of a specific Wnt inhibitor XAV $939^{19}$ to abolish the TCF/LEF promoter activity lead to loss of BrdU labeling as well as maintenance of cytoplasmic staining of RPE65 and junctional staining of $\mathrm{N}$-cadherin, ZO-1, and Na,K-ATPase (Figure 5). Proliferation promoted by EGF + FGF-2 was also abolished by the addition of TGF- $\beta 1$, which suppressed the TCF/LEF promote activity (Figure 5). In addition, overexpression of stable S33Y $\beta$-catenin replicated the effect by EGF-FGF-2 (Figure 4) and rescued the inhibitory effect of XAV939 with regard to proliferation and EMT (Figure 5). These findings, to our best knowledge, are the first demonstrating a clear causative role of the canonical Wnt signaling in triggering proliferation when contact inhibition is disrupted by EGTA. Given that EGTA disrupts the cadherin-mediated homophilic interaction between cell-cell contacts, ${ }^{33}$ selective activation of the Wnt signaling only by subsequent addition of EGF + FGF-2 must have stabilized cytoplasmic $\beta$-catenin to avoid ubiquitin-mediated degradation so as to allow nuclear translocation. ${ }^{34}$ This notion is suggested by the findings that EGF is linked to Wnt3a-induced proliferation via $\mathrm{Wnt} / \beta$-catenin pathway ${ }^{35}$ and that tyrosine kinases activated via bFGF can increase $\beta$-catenin signaling in the nucleus. ${ }^{36}$ Although the evolutionally conserved Hippo signaling is involved in regulating organ size in vivo and contact inhibition in vitro by governing cell proliferation and apoptosis, ${ }^{17}$ our study did not show its involvement when contact inhibition was perturbed by EGTA followed by EGF + FGF- 2 .

Nonetheless, contact inhibition disrupted by EGTA ran the risk of developing EMT. Although EMT is commonly noted in pre-confluent $\mathrm{RPE},{ }^{37,38}$ it requires disruption of cell junctions when TGF- $\beta 2$ is added in porcine RPE explants ${ }^{4}$ and when TGF- $\beta 1$ is added in other confluent epithelial cells. ${ }^{39,40}$ Consistent with the above findings, we also noted that TGF- $\beta 1$ induced EMT in post-confluent ARPE-19 cells only when EGTA was added (Figure 3 ). TGF- $\beta$ is generally regarded as a potent initiator of EMT via Smad or non-Smad pathways. ${ }^{13}$ The canonical Smad signaling in response to TGF $\beta 1$ involves phosphorylation of $\operatorname{Smad} 2 / 3$, which then dimerizes with Smad4 to translocate to the nucleus, where they then regulate the transcription of TGF- $\beta$-responsive genes (reviewed by Massague et $a l^{41}$ ). For EMT, p-Smad2/3 binds with the transcription factors, ZEB1 and ZEB2, to repress epithelial gene expression. ${ }^{14,15}$ It remains unclear whether expression of ZEB1 and ZEB2 will also upregulate mesenchymal genes. Our study confirmed that EGTA alone could not, but with TGF- $\beta 1$ indeed increased nuclear levels of p-Smad2/3, ZEB1, and ZEB2 (Figure 6). The Smad/ZEB1/2 signaling induced by exogenous TGF- $\beta 1$ differs from simple overexpression of ZEB1 via knockdown of YAP and TAZ performed by Liu et $a l^{16}$ as the former suppresses proliferation, while the latter promotes proliferation. Another difference is that our study did not show any change in the Hippo signaling, while the study by Liu et $a l^{16}$ showed nuclear translocation of TAZ-TEAD1. Further investigation is needed to delineate how the Hippo signaling might be activated in post-confluent contact-inhibited ARPE-19 cells. Our study suggested an additive role between EGF and FGF-2 
because neither of EGF and FGF-2 was sufficient to promote proliferation and the TCF/LEF promoter activity.

Unlike TGF- $\beta 1$, EGF and/or FGF-2 notably promoted BrdU labeling (Figure 2), while like TGF- $\beta 1$, EGF + FGF-2 also led to EMT (Figure 3). The notion that the Wnt signaling can be involved in EMT has been shown in other epithelial cells (reviewed by Polette et $a l^{42}$ ). Either FGF-2 or EGF promotes expression of Slug and Snail important for increased cell migration and EMT via Ras/Raf/MAPK pathway. ${ }^{28}$ Importantly, canonical Wnt signaling activated by EGF + FGF-2 was sufficient to activate Smad/ZEB signaling as judged by an increase of nuclear staining and proteins of p-Smad2/3, ZEB1, and ZEB2 (Figure 6). Previously, several studies have shown that Wnt signaling may cooperate with TGF- $\beta$ in inducing complete EMT in proximal tubular epithelial cell lines ${ }^{39}$ and mouse epithelial cells. ${ }^{43}$ Because addition of XAV939 to inhibit Wnt signaling did not completely eliminate Smad signaling, future studies are needed to determine whether EGF + FGF-2 might also activate Smad signaling through pathways other than Wnt signaling. Our study also disclosed a surprising finding that there appeared to be an additive relationship between EGF + FGF-2 and TGF- $\beta 1$ in activating Smad signaling (Figure 6). This finding appeared contradictory to the common belief that FGF-2 counteracts with TGF- $\beta$ in growth promotion and myofibroblast differentiation of corneal keratocytes ${ }^{44}$ and retinal pericytes. ${ }^{45}$ Nonetheless, it was consistent with a recent report where FGF-2 promotes wound repair in confluent mitral valve interstitial cells stimulated by TGF- $\beta 1$ via Smad2/3 signaling. ${ }^{46}$ The discrepancy might lie in the caveat that FGF- 2 acts against TGF- $\beta$ in subconfluent cultures, ${ }^{47}$ but additively with TGF- $\beta$ in confluent cultures. ${ }^{46}$ In the latter, FGF-2 binds to betaglycan, that is, TGF- $\beta$ type III receptor upregulated during confluence, to counteract betaglycan's action against TGF- $\beta$ Smad signaling. ${ }^{46}$ Herein, we disclosed another mechanism that EGF + FGF-2 might work additively with TGF- $\beta 1$ by activating Smad/ZEB1/2 signaling. Future studies are also needed to determine whether such cooperation may occur only in post-confluent, but not pre-confluent cultures.

All clinical pathologies linking to EMT have been shown to be regulated by soluble growth factors or cytokines, including EGF, FGF, HGF, and TGF- $\beta$. Among them, TGF- $\beta$ and FGF can be secreted by RPE cells, ${ }^{48}$ FGF- 2 can be secreted from Bruch's membrane, while TGF- $\beta 1$ is found in the vitreous and subretinal fluids. ${ }^{49}$ Using the model of post-confluent ARPE-19 cells, we confirm that disruption of cell junctions by injuries is indeed an important pre-requisite, but not sufficient to lead to EMT. Upon disruption of cell junctions to perturb contact inhibition, proliferation is uniquely promoted by EGF + FGF-2, but suppressed by TGF- $\beta 1$. Our study further concludes that EMT with proliferation is likely mediated by canonical Wnt signaling, which is sufficient and synergized with TGF- $\beta 1$ in activating the Smad/ZEB1/2 signaling responsible for EMT. Such a scheme summarized in

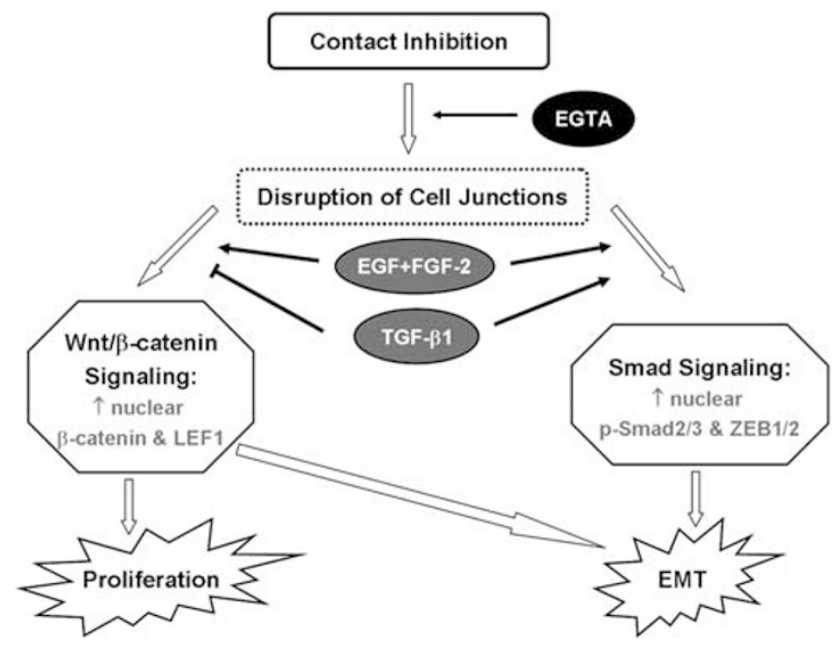

Figure 7 Scheme of canonical Wnt signaling and Smad/ZEB1/2 signaling in regulating epithelial-mesenchymal transition (EMT) with or without proliferation by growth factors. Upon disruption of contact inhibition, epidermal growth factor + fibroblast growth factor-2 (EGF + FGF-2) promotes EMT with proliferation via activating Wnt/ $\beta$-catenin signaling, while transforming growth factor- $\beta 1$ (TGF- $\beta 1$ ) promotes EMT without proliferation via Smad/ZEB1/2 signaling. Wnt $/ \beta$-catenin signaling promoted by EGF + FGF-2 is sufficient and synergized with TGF- $\beta 1$ in activating Smad/ ZEB1/2 signaling responsible for EMT.

Figure 7 can be used as a framework to dissect into the complexity of different cytokine/growth factors that may interplay in a variety of pathological scenarios to explain how proliferation may be promoted or curtailed where RPE undergoes EMT.

Supplementary Information accompanies the paper on the Laboratory Investigation website (http://www.laboratoryinvestigation.org)

\section{ACKNOWLEDGEMENTS}

Tseng SCG was sponsored by R43 EY002502 from the National Eye Institute, National Institutes of Health, Bethesda, MD, USA, and by a research Grant from TissueTech, Miami, FL, USA. Chen HCJ was sponsored by Chang Gung Memorial Hospital (CMRPG-340191) and National Science Council (NSC1002918-I-182A-001) in Taiwan. The content is solely the responsibility of the authors and does not necessarily represent the official views of the National Institutes of Health.

\section{DISCLOSURE/CONFILCT OF INTEREST}

The authors declare no conflict of interest.

1. Strauss $O$. The retinal pigment epithelium in visual function. Physiol Rev 2005;85:845-881.

2. Binder S, Stanzel BV, Krebs I, et al. Transplantation of the RPE in AMD. Prog Retin Eye Res 2007;26:516-554.

3. Kaida M, Cao F, Skumatz CM, et al. Time at confluence for human RPE cells: effects on the adherens junction and in vitro wound closure. Invest Ophthalmol Vis Sci 2000;41:3215-3224.

4. Tamiya S, Liu L, Kaplan HJ. Epithelial-mesenchymal transition and proliferation of retinal pigment epithelial cells initiated upon loss of cell-cell contact. Invest Ophthalmol Vis Sci 2010;51:2755-2763.

5. Kalluri R, Weinberg RA. The basics of epithelial-mesenchymal transition. J Clin Invest 2009;119:1420-1428.

6. Saika S, Yamanaka O, Flanders KC, et al. Epithelial-mesenchymal transition as a therapeutic target for prevention of ocular tissue fibrosis. Endocr Metab Immune Disord Drug Targets 2008;8:69-76. 
7. Nagasaki $\mathrm{H}$, Shinagawa K, Mochizuki M. Risk factors for proliferative vitreoretinopathy. Prog Retin Eye Res 1998;17:77-98.

8. Pastor JC, de la Rua ER, Martin F. Proliferative vitreoretinopathy: risk factors and pathobiology. Prog Retin Eye Res 2002;21:127-144.

9. Huang SS, Huang JS. TGF-beta control of cell proliferation. J Cell Biochem 2005;96:447-462.

10. Lee $\mathrm{H}, \mathrm{O}^{\prime}$ Meara SJ, O'Brien $\mathrm{C}$, et al. The role of gremlin, a BMP antagonist, and epithelial-to-mesenchymal transition in proliferative vitreoretinopathy. Invest Ophthalmol Vis Sci 2007;48:4291-4299.

11. Itoh $\mathrm{Y}$, Kimoto $\mathrm{K}$, Imaizumi $\mathrm{M}$, et al. Inhibition of RhoA/Rho-kinase pathway suppresses the expression of type I collagen induced by TGFbeta2 in human retinal pigment epithelial cells. Exp Eye Res 2007;84:464-472.

12. Lee J, Moon HJ, Lee JM, et al. Smad3 regulates Rho signaling via NET1 in the transforming growth factor-beta-induced epithelialmesenchymal transition of human retinal pigment epithelial cells. J Biol Chem 2010;285:26618-26627.

13. Heldin $\mathrm{CH}$, Landstrom $\mathrm{M}$, Moustakas A. Mechanism of TGF-beta signaling to growth arrest, apoptosis, and epithelial-mesenchymal transition. Curr Opin Cell Biol 2009;21:166-176.

14. Postigo AA. Opposing functions of ZEB proteins in the regulation of the TGFbeta/BMP signaling pathway. EMBO J 2003;22:2443-2452.

15. Shirakihara T, Saitoh M, Miyazono K. Differential regulation of epithelial and mesenchymal markers by deltaEF1 proteins in epithelialmesenchymal transition induced by TGF-beta. Mol Biol Cell 2007; 18:3533-3544

16. Liu $Y$, Xin $Y, Y e F$, et al. Taz-tead1 links cell-cell contact to zeb1 expression, proliferation, and dedifferentiation in retinal pigment epithelial cells. Invest Ophthalmol Vis Sci 2010;51:3372-3378.

17. Zeng $Q$, Hong $W$. The emerging role of the hippo pathway in cell contact inhibition, organ size control, and cancer development in mammals. Cancer Cell 2008;13:188-192.

18. Chu WK, Dai PM, Li HL, et al. Glycogen synthase kinase- $3 \beta$ regulates $\Delta$ Np63 gene transcription through the $\beta$-catenin signaling pathway. J Cell Biochem 2008;105:447-453.

19. Huang SM, Mishina YM, Liu S, et al. Tankyrase inhibition stabilizes axin and antagonizes Wnt signalling. Nature 2009;461:614-620.

20. McKay BS, Irving PE, Skumatz CM, et al. Cell-cell adhesion molecules and the development of an epithelial phenotype in cultured human retinal pigment epithelial cells. Exp Eye Res 1997;65:661-671.

21. Ban Y, Rizzolo LJ. A culture model of development reveals multiple properties of RPE tight junctions. Mol Vis 1997;3:18.

22. Okami T, Yamamoto A, Omori $\mathrm{K}$, et al. Immunocytochemical localization of $\mathrm{Na}+, \mathrm{K}(+)$-ATPase in rat retinal pigment epithelial cells. J Histochem Cytochem 1990;38:1267-1275.

23. Zeisberg $M$, Neilson EG. Biomarkers for epithelial-mesenchymal transitions. J Clin Invest 2009;119:1429-1437.

24. Schneider M, Hansen JL, Sheikh SP. S100A4: a common mediator of epithelial-mesenchymal transition, fibrosis and regeneration in diseases? J Mol Med 2008;86:507-522.

25. Stein U, Arlt F, Walther W, et al. The metastasis-associated gene S100A4 is a novel target of beta-catenin/T-cell factor signaling in colon cancer. Gastroenterology 2006;131:1486-1500.

26. Varelas $\mathrm{X}$, Miller BW, Sopko R, et al. The Hippo pathway regulates Wnt/ beta-catenin signaling. Dev Cell 2010;18:579-591.

27. Heallen $T$, Zhang $M$, Wang J, et al. Hippo pathway inhibits Wnt signaling to restrain cardiomyocyte proliferation and heart size. Science 2011;332:458-461.

28. $\mathrm{Xu} \mathrm{J}$, Lamouille $\mathrm{S}$, Derynck R. TGF-beta-induced epithelial to mesenchymal transition. Cell Res 2009;19:156-172.

29. Burke JM, Hong J. Fate of E-cadherin in early RPE cultures: transient accumulation of truncated peptides at nonjunctional sites. Invest Ophthalmol Vis Sci 2006;47:3635-3643.
30. Kivela $T$, Uusitalo $M$. Structure, development and function of cytoskeletal elements in non-neuronal cells of the human eye. Prog Retin Eye Res 1998;17:385-428.

31. Tholozan FM, Gribbon C, Li Z, et al. FGF-2 release from the lens capsule by MMP-2 maintains lens epithelial cell viability. Mol Biol Cell 2007; 18:4222-4231.

32. Moustakas A, Pardali K, Gaal A, et al. Mechanisms of TGF-beta signaling in regulation of cell growth and differentiation. Immunol Lett 2002;82:85-91.

33. Chitaev NA, Troyanovsky SM. Direct $\mathrm{Ca}^{2+}$-dependent heterophilic interaction between desmosomal cadherins, desmoglein and desmocollin, contributes to cell-cell adhesion. J Cell Biol 1997; 138:193-201

34. Nelson WJ, Nusse R. Convergence of Wnt, beta-catenin, and cadherin pathways. Science 2004;303:1483-1487.

35. Kim SE, Choi KY. EGF receptor is involved in WNT3a-mediated proliferation and motility of NIH3T3 cells via ERK pathway activation. Cell Signal 2007;19:1554-1564.

36. Ciruna B, Rossant J. FGF signaling regulates mesoderm cell fate specification and morphogenetic movement at the primitive streak. Dev Cell 2001;1:37-49.

37. Lee SC, Kwon OW, Seong GJ, et al. Epitheliomesenchymal transdifferentiation of cultured RPE cells. Ophthalmic Res 2001; 33:80-86.

38. Parapuram SK, Chang B, Li L, et al. Differential effects of TGFbeta and vitreous on the transformation of retinal pigment epithelial cells. Invest Ophthalmol Vis Sci 2009;50:5965-5974.

39. Masszi A, Fan L, Rosivall L, et al. Integrity of cell-cell contacts is a critical regulator of TGF-beta 1-induced epithelial-tomyofibroblast transition: role for beta-catenin. Am J Pathol 2004;165: 1955-1967.

40. Fan L, Sebe A, Peterfi $Z$, et al. Cell contact-dependent regulation of epithelial-myofibroblast transition via the rho-rho kinase-phosphomyosin pathway. Mol Biol Cell 2007;18:1083-1097.

41. Massague J, Seoane J, Wotton D. Smad transcription factors. Genes Dev 2005; 19:2783-2810.

42. Polette $M$, Mestdagt $M$, Bindels $S$, et al. Beta-catenin and ZO-1: shuttle molecules involved in tumor invasion-associated epithelialmesenchymal transition processes. Cells Tissues Organs 2007;185: 61-65.

43. Eger A, Stockinger A, Park J, et al. beta-Catenin and TGFbeta signalling cooperate to maintain a mesenchymal phenotype after FosER-induced epithelial to mesenchymal transition. Oncogene 2004; 23:2672-2680.

44. Maltseva $\mathrm{O}$, Folger $\mathrm{P}$, Zekaria $\mathrm{D}$, et al. Fibroblast growth factor reversal of the corneal myofibroblast phenotype. Invest Ophthalmol Vis Sci 2001; 42:2490-2495.

45. Papetti M, Shujath J, Riley KN, et al. FGF-2 antagonizes the TGF-beta1mediated induction of pericyte alpha-smooth muscle actin expression: a role for myf-5 and Smad-mediated signaling pathways. Invest Ophthalmol Vis Sci 2003;44:4994-5005.

46. Han L, Gotlieb Al. Fibroblast growth factor-2 promotes in vitro mitral valve interstitial cell repair through transforming growth factor-beta/ Smad signaling. Am J Pathol 2011;178:119-127.

47. Cushing MC, Mariner PD, Liao JT, et al. Fibroblast growth factor represses Smad-mediated myofibroblast activation in aortic valvular interstitial cells. FASEB J 2008;22:1769-1777.

48. Charteris DG. Proliferative vitreoretinopathy: pathobiology, surgical management, and adjunctive treatment. Br J Ophthalmol 1995;79: 953-960.

49. Baudouin $C$, Fredj-Reygrobellet $D$, Brignole $F$, et al. Growth factors in vitreous and subretinal fluid cells from patients with proliferative vitreoretinopathy. Ophthalmic Res 1993;25:52-59. 